\title{
Multivariable Adaptive Hybrid Control Model for Interconnected Power Systems at the Inception of Voltage Collapse
}

\author{
Nihat Pamuk \\ Türkiye Elektrik Iletim Anonim Şirketi, 5. Iletim Tesis ve Işletme Grup Müdürlüğü, Sakarya \\ e-posta:nihatpamuk@gmail.com
}

Geliş Tarihi:24.09.2014; Kabul Tarihi:09.04.2015

\begin{tabular}{cl} 
Abstract \\
\cline { 2 - 3 } $\begin{array}{c}\text { Keywords } \\
\text { Multivariable adaptive }\end{array}$ & $\begin{array}{l}\text { Power systems are one of the largest and most intricate nonlinear systems in the world. Bifurcations } \\
\text { phenomena are not rather mundane phenomena in electrical power systems. Bifurcations phenomena } \\
\text { is determined to be vital factors at the inception of voltage collapse. In this study, multivariable } \\
\text { hybrid control (MAHC); } \\
\begin{array}{c}\text { Bifurcation; Power } \\
\text { systems; Voltage }\end{array}\end{array} \quad \begin{array}{l}\text { systems. The proposed control system comprises nonlinear controller ineffectiveness. The interaction } \\
\text { terms, and then gains are optimally and automatically tuned using expert systems. Robust } \\
\text { collapse }\end{array}$ \\
$\begin{array}{l}\text { computational tools for bifurcation analysis have been performed in order to investigation significant } \\
\text { multivariable adaptive problems arising in electrical power systems. The multivariable adaptive hybrid } \\
\text { controller gives better initial response than invariable controller. The simulation results show that this } \\
\text { new method is capable of controlling the system effectively. }\end{array}$
\end{tabular}

\section{Gerilim Çökmesi Başlangıcındaki Enterkonnekte Güç Sistemleri için Çok Değişkenli Uyarlanabilir Hibrit Kontrol Modeli}

\author{
Anahtar Kelimeler \\ Çok değişkenli \\ uyarlanabilir hibrit \\ kontrol (ÇDUHK); \\ Çatallaşma; Güç \\ sistemleri; Gerilim \\ çökmesi
}

\begin{abstract}
Özet
Güç sistemleri, dünyadaki en büyük ve en karmaşık doğrusal olmayan sistemlerden biridir. Çatallaşma olayları elektrik güç sistemlerinde sıradan olaylar değildir. Çatallaşma olayları gerilim çökmesi başlangııındaki önemli etmenler olarak tespit edilmektedir. Bu çalışmada, çok değişkenli uyarlanabilir hibrit kontrolörün davranışları elektrik güç sistemlerinde çatallaşmayı kontrol etmek amacıyla önerilmektedir. Önerilen kontrol sistemi doğrusal olmayan kontrolörün etkisizliğinden oluşmaktadır. Uzman sistemler kullanılarak etkileşim şartları ve sonrasındaki kazançları en uygun şekilde otomatik olarak ayarlanmıştır. Çatallaşma analizi için güçlü hesaplama araçları, elektrik güç sistemlerinde ortaya çıkan önemli çok değişkenli uyarlanabilir sorunları incelemek amacıyla uygulanmıştır. Çok değişkenli uyarlanabilir hibrit kontrolör, ilk tepkiyi değişkensiz kontrolörden daha iyi verir. Simülasyon sonuçları bu yeni yöntemin etkili bir kontrol sistemi olduğunu göstermektedir.
\end{abstract}

(C) Afyon Kocatepe Üniversitesi

\section{Introduction}

Nowadays, there are many engineering systems problems so complex in their structure that it is not possible to effective control them via a single classic variable controller. It is becoming increasingly important for power system planning and operating engineers to be capable of performing comprehensive voltage stability analyses of the systems. This need is largely due to the recent trends towards operating systems under stressed conditions as a result of increasing system loads without sufficient transmission and generation enhancements. There have been many failures, due to voltage instability in interconnected power systems around the world (Thukaram et al. 1998). In recent years voltage stability and voltage collapse phenomena have become more and more important issues in interconnected power system analysis and control. In fact, there is no unique formal definition for large scale interconnected power systems, but according to a more didactic viewpoint, which is accepted by almost all engineers in control and system community, a system is called large scale if it can

be

partitioned 
in to a number of interconnected power subsystems, either for numerical or practical reasons, in a way that the behavior of each subsystems is affected by the behavior of other power subsystems (Sun et al. 2009 ; Revel et al. 2008).

Interconnected power systems blackouts have received a great attention in the last few years, due to the increasing amount of incidents occurred in many countries around the world. For different reasons many power systems are forced to operate near to their stability limits and thus they are vulnerable to perturbations of the operating conditions. When these limits are exceeded, the system can exhibit undesired transient responses with the impossibility to retain a stable voltage profile. This phenomenon is known as voltage collapse (Saad et al. 2005).

Several techniques (Canizares et al 1996 ; Zambroni et al. 1997) allow the determination of the load margin in relation to the voltage collapse, as well as the system critical bus, for a current and expanding load condition, and availability of generating and transmission equipment. Considering the stochastic nature of these parameters, the impact on the load flow results has been the object of several studies (Anders 1990 ; Leite and Silva 1990), which can be extended to deal with the voltage collapse problem.

Analytical techniques based on convolution as well as Monte Carlo simulation (Rubinstein 1981) have been extensively used in the probabilistic analysis. The incorporation of some probabilistic aspects into the problem of voltage stability has already received some attention (Sobierajski 1994 ; Billinton and Aboreshaid 1998). The modeling of several types of load uncertainties (Leite et al. 1990), as well as the simulation of equipment unavailability (Aboreshaid and Billinton 1999 ; Billinton and Aboreshaid 1998), can provide much more realistic measures for the risk of voltage collapse.
A lot of factors that influence it are increments in the load consumption that reach the limits of the network or the generation capacity, actions of badly tuned controllers, tripping of lines and generators, among others (Meddad et al. 2013 ; Abed et al. 2004). Power systems are highly nonlinear systems and its dynamical behavior may change qualitatively when parameters are varied. For example, after a load increment a stable operating point may become unstable and oscillations arise. This behavior can be locally associated to a "Hopf Bifurcation" (Öztürk and Gencer 2002).

In general, bifurcation theory can be applied to understand mechanisms leading to nonlinear phenomena in these systems. The idea underlying a bifurcation analysis is to investigate qualitative changes in the system dynamics. The bifurcation theory is one of the most common theory which is used to analysis the problems such as angular and voltage stability in power systems. A general voltage collapse graph and decreases the interconnected power system security margin is shown in figure 1 . Switching of shunt capacitors as load increases can have the tendency to rise to voltage and increase the amount of power that can be transmitted (Hussein and Chen 2003 ; Niglye et al. 2006).

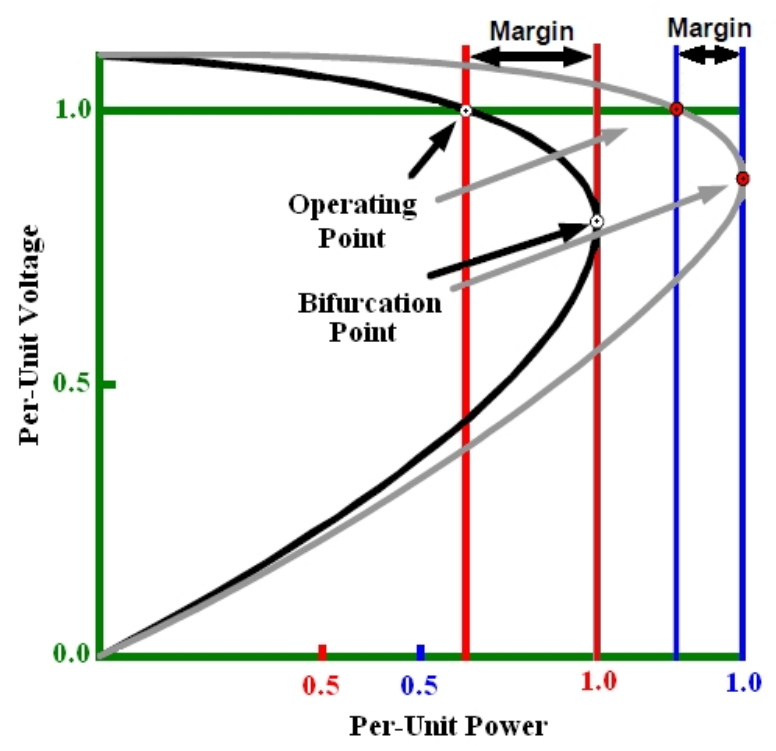

Figure 1. A general voltage collapse security margin in power system. 
Voltage collapse was identified and analyzed for simple power systems in the first half of this century. However, only recently voltage collapses become a serious operating concern. This is a result of the increasing stress being placed on today's complex power systems. Voltage instabilities leading to power disruptions have occurred in systems throughout the world. The power system research community has responded by focusing significant effort toward the study of voltage instabilities and their control (Tunç, 2011).

\section{Mathematical Model of Power System}

The interconnected power system model is shown in figure 2. The model consists of an infinite bus on the left, a load bus on the center and a generator bus on the right.

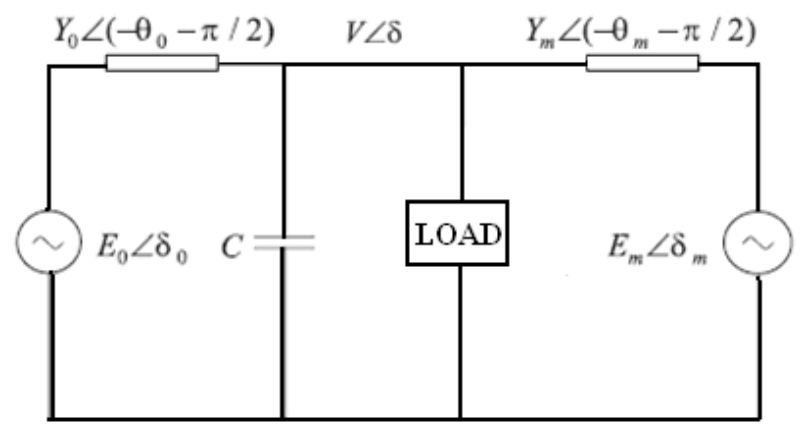

Figure 2. Interconnected power system model.

$\mathrm{Y}_{0} \angle\left(-\theta_{0}-\pi / 2\right)$ and $\mathrm{Y}_{\mathrm{m}} \angle\left(\theta_{\mathrm{m}}-\pi / 2\right)$ are the admittances of the transmission lines. The concept of an infinite bus refers to a particular node of the system with enough capacity to absorb any mismatch in the power balance equations. Thus, it can be considered as a fictitious generator with constant voltage magnitude $E_{0}$ and phase $\delta_{0}$ (usually $E_{0}=1$ and $\delta_{0}=0$ ). This approach is valid especially when working with a small subsystem connected to a large-scale power grid. On the other hand, the generator has constant voltage magnitude $E_{m}$ but the angle $\delta_{\mathrm{m}}$ varies according to the so-called swing equation;

$M \delta_{m}+d m \delta_{m}=P_{m}-P_{e}$

where $M$ is the inertia of the rotor, $\mathrm{dm}$ is the damping coefficient, $P_{m}$ is the mechanical power supplied to the generator and $\mathrm{P}_{\mathrm{e}}$ is the electric power supplied by the generator to the network (including the loss in $Y_{m}$ ) given by (Dobson and Chiang 1989);

$$
P_{e}=-E_{m} Y_{m}\left[E_{m} \operatorname{Sin} \theta_{m}+V \operatorname{Sin}\left(\delta-\delta_{m}+\theta_{m}\right)\right]
$$

Replacing equation 2 in equation 1 , the dynamics of the generator is reproduced by the classical model of a voltage generator also known as constant voltage behind reactance;

$$
\begin{aligned}
& \dot{\delta_{m}}=\omega \\
& \dot{\omega}=\frac{1}{M}\left[-d_{m} \omega+P_{m}+\left(\mathrm{E}_{m}\right)^{2} Y_{m} \operatorname{Sin} \theta_{m}\right. \\
& \left.+E_{m} V Y_{m} \operatorname{Sin}\left(\delta-\delta_{m}+\theta_{m}\right)\right]
\end{aligned}
$$

The load bus, with voltage magnitude $\mathrm{V}$ and phase $\delta$, consists of an induction motor, a load P-Q and a capacitor $\mathrm{C}$. The dynamics of this part is derived from a power balance at the bus. Considering an empirical model for the induction motor and a static load $P-Q$, the power consumption results;

$$
\begin{gathered}
P_{\text {load }}=P_{0}+k_{p \omega} \dot{\delta}+k_{p v}(\mathrm{~V}+\mathrm{T} \dot{V})+P_{1} \\
Q_{\text {load }}=Q_{0}+k_{q \omega} \dot{\delta}+k_{q v} \mathrm{~V}+k_{q v^{2}} \mathrm{~V}^{2}+Q_{1}
\end{gathered}
$$

where $T, k_{p \omega}, k_{p v}, k_{q \omega}, k_{q v}$ and $k_{q v 2}$ are constants of the motor, $\mathrm{P}_{0}, \mathrm{Q}_{0}$ and $\mathrm{P}_{1}, \mathrm{Q}_{1}$ are the static active and reactive power drained by the motor and the load P-Q, respectively (Walve 1986 ; Wang et al. 1994). In terms of bus voltages and transmission lines admittances, the active and reactive power supplied to the load are;

$$
\begin{gathered}
P\left(\delta_{m}, \delta, V\right)=-E_{0}{ }^{\prime} Y_{0}{ }^{\prime} V \operatorname{Sin}\left(\delta+\theta_{0}{ }^{\prime}\right)-E_{m} Y_{m} \\
V \operatorname{Sin}\left(\delta-\delta_{m}+\theta_{m}\right)+V^{2}\left[Y_{0}{ }^{\prime} \operatorname{Sin}\left(\theta_{0}{ }^{\prime}\right)+Y_{m} \operatorname{Sin}\left(\theta_{m}\right)\right] \\
Q\left(\delta_{m}, \delta, V\right)=E_{0}{ }^{\prime} Y_{0}{ }^{\prime} V \operatorname{Cos}\left(\delta+\theta_{0}{ }^{\prime}\right)+E_{m} Y_{m} \\
V \operatorname{Cos}\left(\delta-\delta_{m}+\theta_{m}\right)-V^{2}\left[Y_{0}{ }^{\prime} \operatorname{Cos}\left(\theta_{0}^{\prime}\right)+Y_{m} \operatorname{Cos}\left(\theta_{m}\right)\right]
\end{gathered}
$$

where $E_{0}{ }^{\prime}, Y_{0}{ }^{\prime}, \theta_{0}{ }^{\prime}$ are obtained from a thevenin 
equivalent of the circuit towards the infinite bus including the capacitor $\mathrm{C}$. Their expressions are;

$E_{0}^{\prime}=\frac{E_{0}}{\Gamma}$

$Y_{0}^{\prime}=Y_{0} \cdot \Gamma$

$\theta_{0}^{\prime}=\theta_{0}+\tan ^{-1} \frac{C . Y^{-1} \operatorname{Sin}\left(\theta_{0}\right)}{1-C \cdot Y_{0}^{-1} \operatorname{Cos}\left(\theta_{0}\right)}$

$\Gamma=\sqrt{1+C^{2} Y_{0}^{-2}-2 C Y_{0}^{-1} \operatorname{Cos}\left(\theta_{0}\right)}$

Then the balance between the supplied power $(\mathrm{P}$, $Q$ ) and the drained power ( $\left.P_{\text {load }}, Q_{\text {load }}\right)$ at the load bus results in;

$$
\begin{aligned}
& P\left(\delta_{m}, \delta, \mathrm{V}\right)=P_{0}+k_{p \omega} \dot{\delta}+k_{p v}(\mathrm{~V}+\mathrm{T} \dot{V})+P_{1} \\
& Q\left(\delta_{m}, \delta, \mathrm{V}\right)=Q_{0}+k_{q \omega} \dot{\delta}+k_{q v} \mathrm{~V}+k_{q v^{2}} \mathrm{~V}^{2}+Q_{1} \\
& \dot{\delta}=\left(\frac{1}{k_{q \omega}}\right) \cdot\left[-\mathrm{k}_{q v^{2}} \mathrm{~V}^{2}-k_{q v} V-Q_{0}-Q_{1}+Q\left(\delta_{m}, \delta, \mathrm{V}\right)\right]
\end{aligned}
$$

Substituting equation 14 into equation 12 and solving for $\mathrm{V}$, results;

$$
\begin{aligned}
& \dot{V}=\left(\frac{1}{T k_{q \omega} k_{p v}}\right)\left\{\mathrm{k}_{p \omega} k_{q \nu^{2}} V^{2}+\left(k_{p \omega} k_{q v}-k_{q \omega} k_{p v}\right) V+\right. \\
& \left.k_{q \omega}\left[P\left(\delta_{m}, \delta, \mathrm{V}\right)-\mathrm{P}_{0}-P_{1}\right]-k_{p \omega}\left[\mathrm{Q}\left(\delta_{m}, \delta, \mathrm{V}\right)-Q_{0}-Q_{1}\right]\right\}
\end{aligned}
$$

Equations $3,4,14,15$ with $\dot{P}$ and $\dot{Q}$ given by equation 6 and equation 7 respectively. Describe the dynamics of the interconnected power system model in terms of the state variables $\delta_{m}, \omega, \delta$ and $V$ (Liu et al. 2011). The free parameters used in the bifurcation analysis are $Q_{1}$ and $P_{1}$. The reactive and active power drained by the static $\mathrm{P}-\mathrm{Q}$ load (Tunç, 2011 ; Karsenti et al. 1996).

\section{Control System Strategies and Design}

Interconnected power systems are always controlled and operated in different modes of operation where control objectives and strategies are different from each other and should be illustrated in detail, respectively.

\subsection{First level control strategies and design}

In this step, the goal is to design a linear adaptive controller such that the interaction term would be neutralized, and so the power subsystems would be completely decoupled. Thus the linear adaptive control signal is chosen to be;

$U_{k}=-g_{n k}^{-1}\left(\overline{\mathrm{x}_{k}}\right) \sum_{\substack{j=1 \\ j \neq k}}^{N} h_{k j}\left(\overline{\mathrm{x}}_{j}\right)+\mathrm{v}_{k}$

where the term $v_{k}$ is a linear adaptive control input to stabilize and guarantee the desired performance for each power subsystem. In fact, $v_{k}$ is the local control input, and $u_{k}-v_{k}$ is $u_{k}{ }^{g}$, which is the global linear control signal for the $\mathrm{k}^{\text {th }}$ subsystem, designed at the first level; which according to the problem assumptions would linearism some part of the system so that the subsystems would be decoupled. Linear adaptive control model is shown in figure 3.
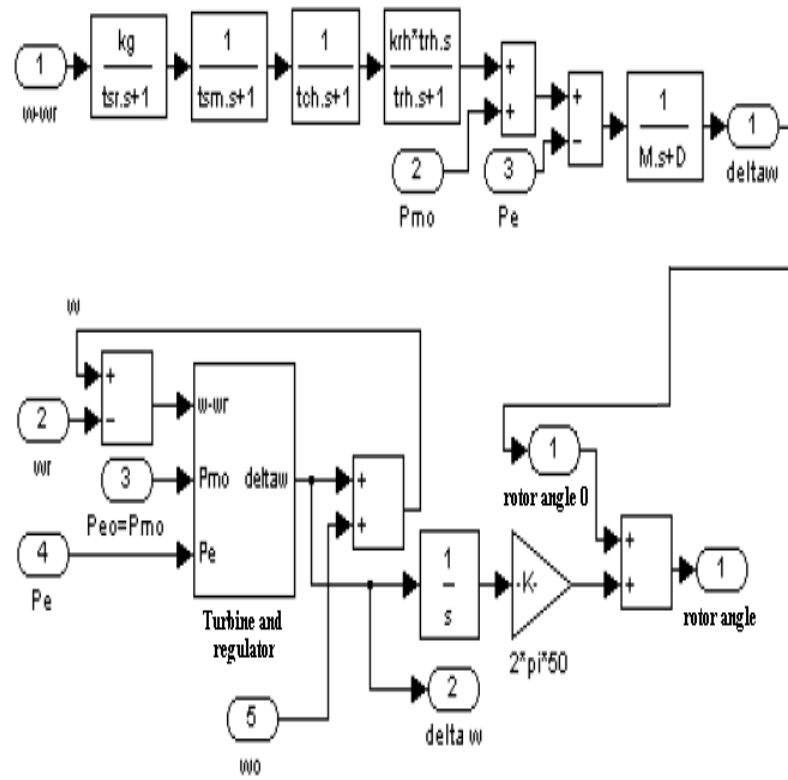

Figure 3. Linear adaptive control model

The values of the fixed parameters used in the following numerical study are obtain from; $M=0.01464, C=3.5, E_{m}=1.05, Y_{0}=3.33, \theta_{0}=\theta_{m}=0$, $\mathrm{k}_{\mathrm{p} \omega}=0.4, \mathrm{k}_{\mathrm{pv}}=0.3, \mathrm{k}_{\mathrm{q} \omega}=-0.03, \mathrm{k}_{\mathrm{qv}}=-2.8, \mathrm{k}_{\mathrm{qv} 2}=2.1$, $\mathrm{T}=8.5, \mathrm{P}_{0}=0.6, \mathrm{Q}_{0}=1.3, \mathrm{E}_{0}=1, \mathrm{Y}_{\mathrm{m}}=5.0, \mathrm{P}_{\mathrm{m}}=1.0$ and $d_{m}=0.05$. All the constants are normalized according to a given basis ("per-unit" representation), except for the angles which are given in degrees. A simple linear change of 
coordinates; $\delta_{\mathrm{m}}=\mathrm{x}_{1}, \omega=\mathrm{x}_{2}, \delta=\mathrm{x}_{3}, \mathrm{v}=\mathrm{x}_{4}$ the model can be cast as;

$x_{1}=x_{2}$

$x_{2}=-3.4153 x_{2}+3.5860656 x_{4} \sin \left(x_{3}-x_{1}\right)+68.306$

$\dot{x_{3}}=242.3333\left(x_{4}\right)^{2} u+33.333 \mathrm{Q}_{1}-x_{4}\left[110.9993333 \cos \left(x_{3}\right)+\right.$

$\left.175 \cos \left(x_{3}-x_{1}\right)+93.3333\right]+43.333$

$\dot{x_{4}}=-38.013058\left(x_{4}\right)^{2}+x_{4}\left[14.52287-1.305869 \sin \left(x_{3}\right)-\right.$

$\left.2.058824 \sin \left(x_{3}-x_{1}\right)+17.4117 \cos \left(\mathrm{x}_{3}\right)+27.45 \cos \left(x_{3}-x_{1}\right)\right]-$

$0.39216 \mathrm{P}_{1}-5.22876 Q_{1}-7.032679$

$\dot{x_{4}}=-38.013058\left(x_{4}\right)^{2}+x_{4}\left[14.52287-1.305869 \sin \left(x_{3}\right)-\right.$

$\left.2.058824 \sin \left(x_{3}-x_{1}\right)+17.4117 \cos \left(\mathrm{x}_{3}\right)+u(\omega)\right]$

$u(\omega)=k * x_{2} \quad$ (For linear adaptive controller)

Simulation results for $\mathrm{P}_{1}=1.015, \mathrm{Q}_{1}=0.685 \mathrm{pu}$ and with the initial conditions $x_{1}=0^{0}, x_{2}=0, x_{3}=10^{\circ}$, $\mathrm{x}_{4}=0.97, \mathrm{t}=0$ have showed in figure 4,5 and 6 . Graphs with control input k $=0.1$

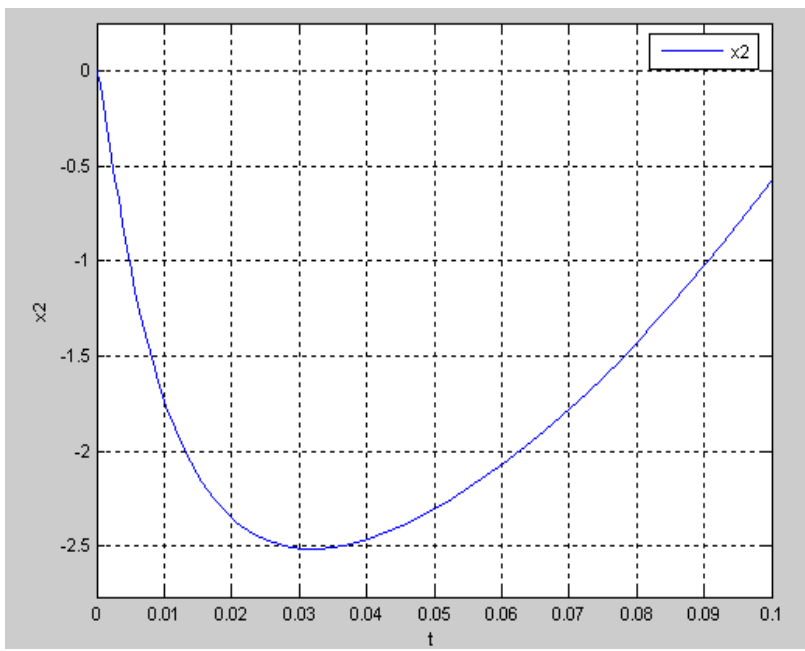

Figure 4. $X_{2}$ state variable changes over time after linear adaptive controller

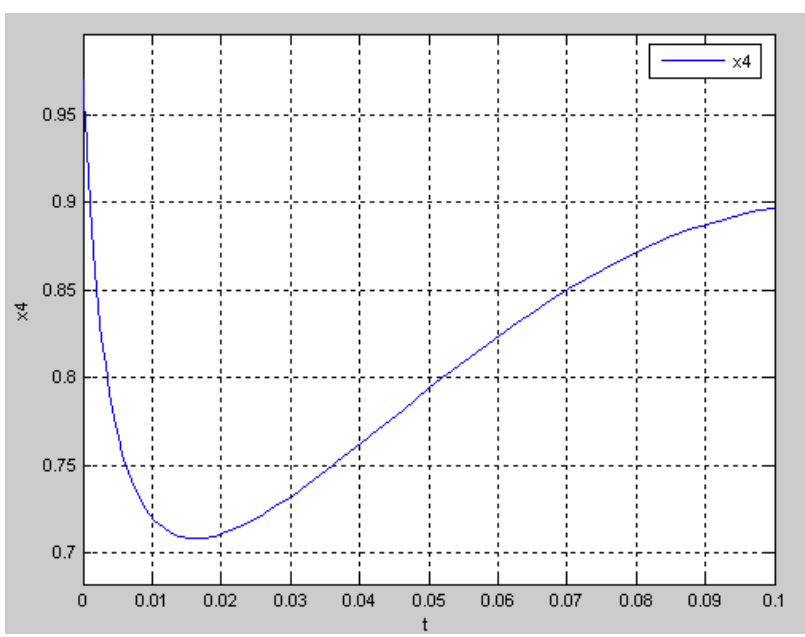

Figure 5. $\mathrm{X}_{4}$ state variable changes over time after linear adaptive controller

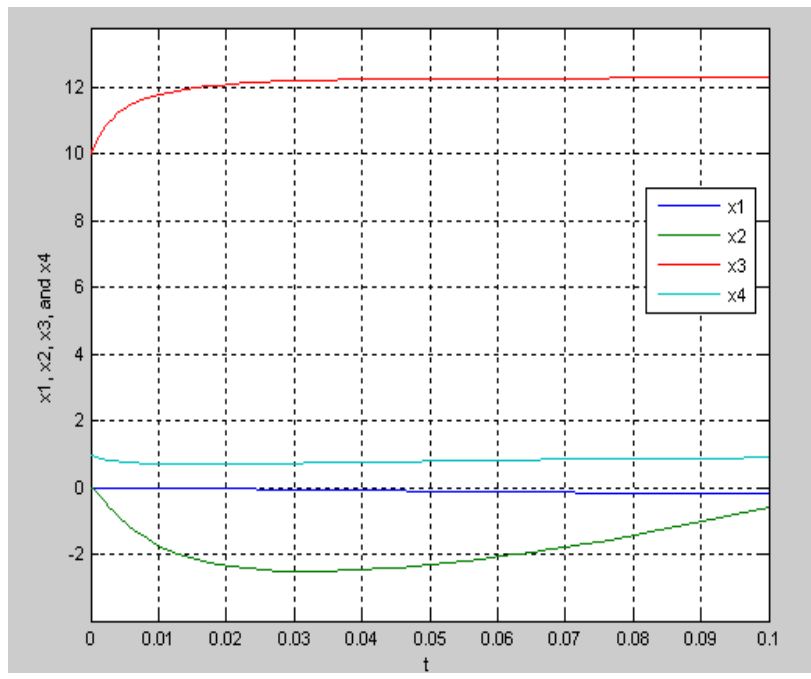

Figure 6. $X_{1}, X_{2}, X_{3}$ and $X_{4}$ state variables change over time after linear adaptive controller

\subsection{Second level control strategies and design}

Since all the interactions are completely neutralized due to the linear adaptive control signal of the first level, the control design at this step could be performed independently. I use adaptive back stepping algorithm to design the control input at this level.

Since the decoupled power subsystems are in strict feedback form, back stepping algorithm might be applied. The nonlinear adaptive control signal is chosen in such a way that the voltage stability function and its time derivative would hold the needed conditions, so that (asymptotic) stability of the equilibrium point of the power system would be assured. 
Since back stepping is a model based technique, developing the schemes that can handle the model uncertainties seems to be essential. Using adaptive approach is one solution for this problem. Adaptive back stepping, which is a nonlinear controller based indirect adaptive method with online parameter estimation, was first introduced in (Astolfi et al. 2008).

In this approach, the control signal and the adaptation law are designed simultaneously, in accordance with the direct nonlinear adaptive control method. Nonlinear adaptive control model is shown in figure 7.

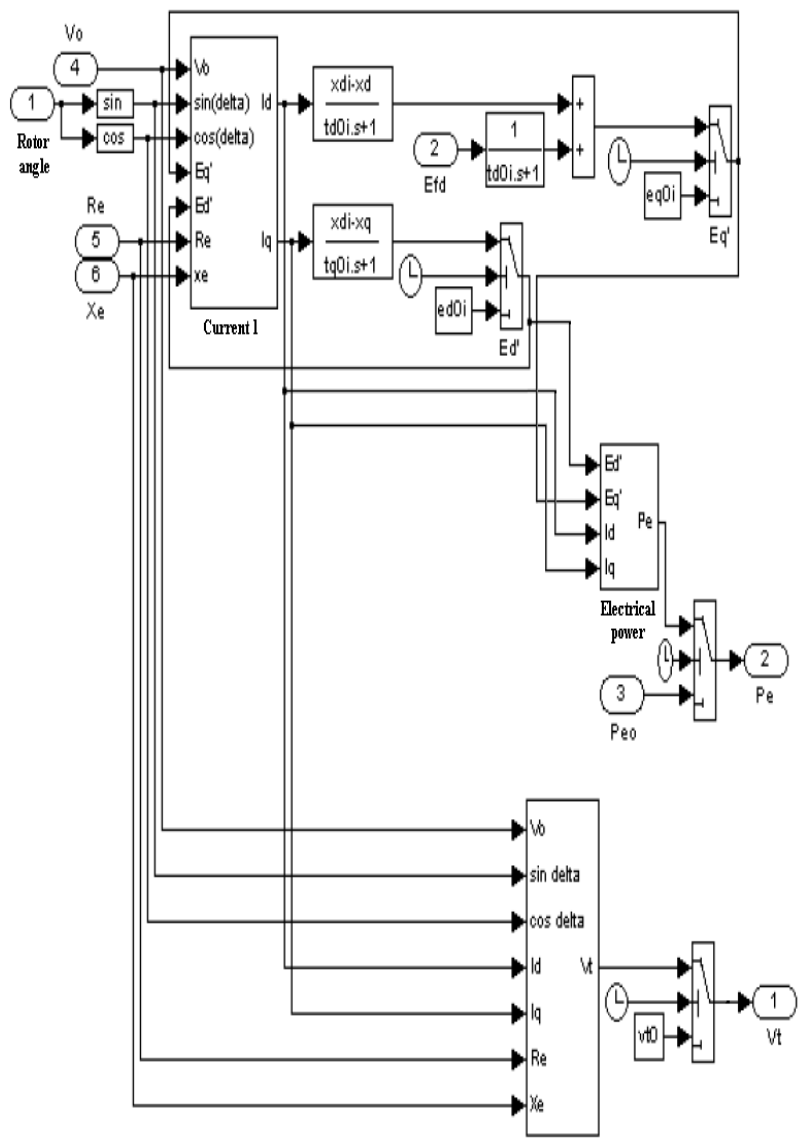

Figure 7. Nonlinear adaptive control model

$\dot{x_{4}}=-38.013058\left(x_{4}\right)^{2}+x_{4}\left[14.52287-1.305869 \sin \left(x_{3}\right)-\right.$ $\left.2.058824 \sin \left(x_{3}-x_{1}\right)+17.4117 \cos \left(\mathrm{x}_{3}\right)+u(\omega)\right]$

$u(\omega)=k *\left(x_{2}\right)^{3}$ (For nonlinear adaptive controller)

Simulation results for $P_{1}=1.015, Q_{1}=0.685$ pu and with the initial conditions $x_{1}=0^{0}, x_{2}=0, x_{3}=10^{\circ}$, $\mathrm{x}_{4}=0.97, \mathrm{t}=0$ have showed in figure 8,9 and 10 . Graphs with control input $k=0.1$

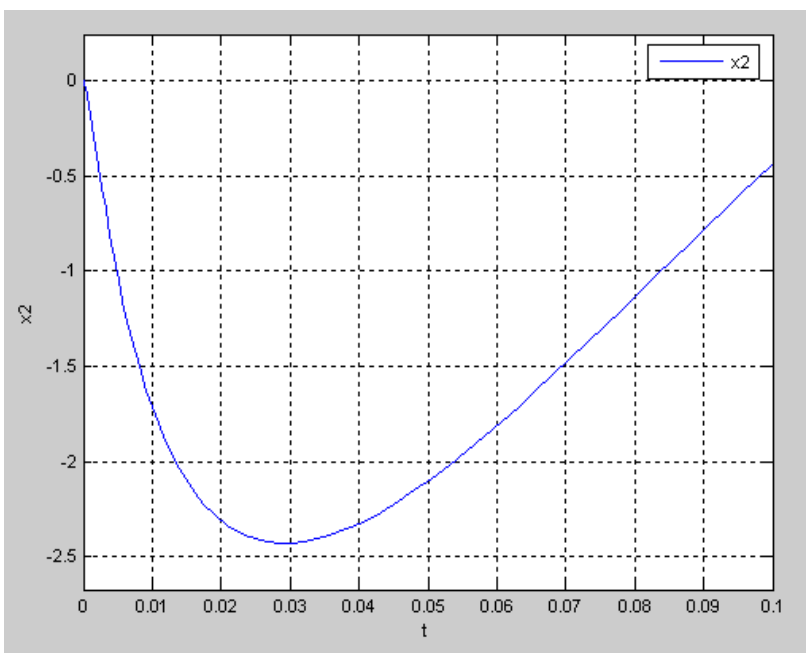

Figure 8. $X_{2}$ state variable changes over time after nonlinear adaptive controller

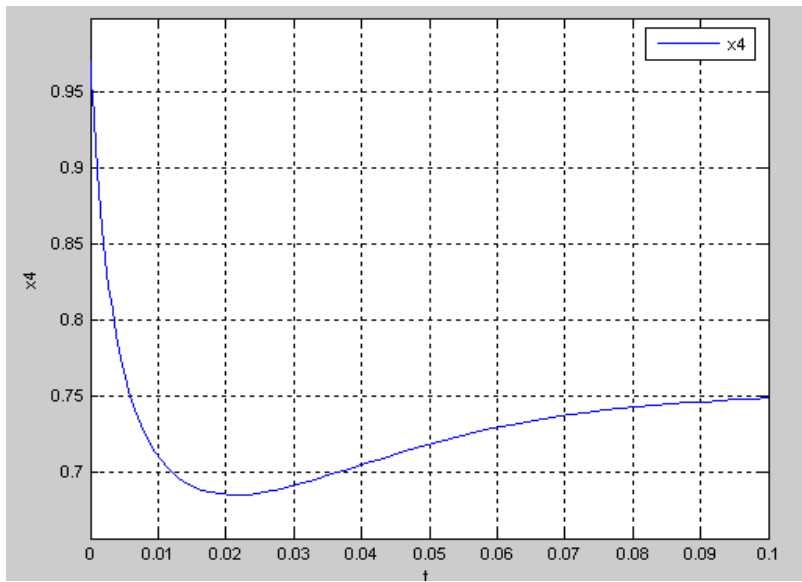

Figure 9. $\mathrm{X}_{4}$ state variable changes over time after nonlinear adaptive controller

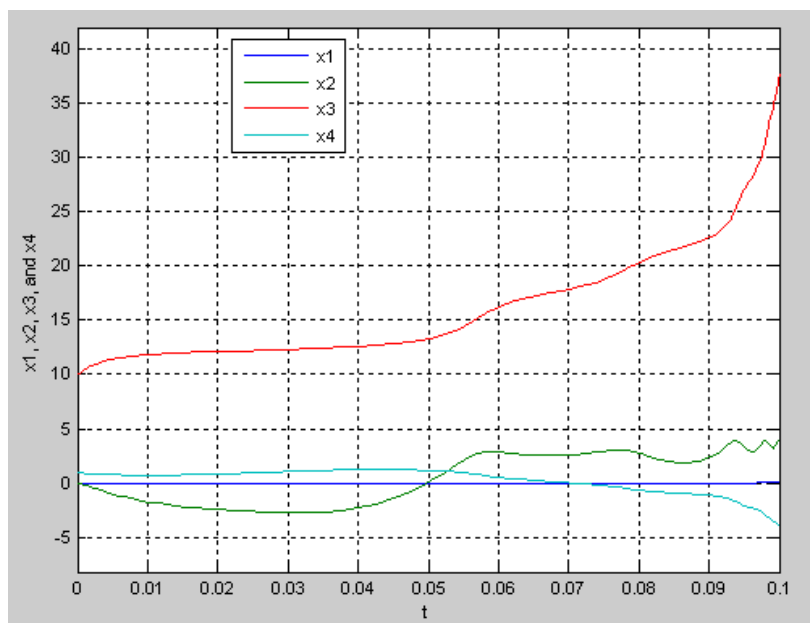

Figure 10. $X_{1}, X_{2}, X_{3}$ and $X_{4}$ state variables change over time after nonlinear adaptive controller

\section{Power System Modeling with MAHC}

Multivariable Adaptive Hybrid Control (MAHC) approaches require precise mathematical model, structure parameters or dynamic characteristics of 
controlled interconnected power system. They can deduce the control commands from input variables by their abilities of learning and generalization.

MAHC is employed to extract the reference commands of generator torque $T_{\text {gref }}$ and pitch angle from the input real time measurements of generator angular velocity $\mathrm{w}_{\mathrm{g}}$ and power $\mathrm{P}_{\mathrm{g}}$. MAHC has strong ability of nonlinear mapping, flexible network architecture, good characteristics of fault tolerance and robustness (Sheng et al. 2011; Pagilla et al. 2007). MAHC has the ability of approximating any nonlinear function with high accuracy and good generalization capability even in the condition of few input samples.

MAHC is proposed in this paper to precisely control the interconnected power system. The MAHC has strong robustness of avoiding external perturbations and parameter variations as compared to conventional controller. Furthermore, this controller also owns the advantages of compactness, easy implementation. As described in equation 17, there exists a conditional mean between the dependent stochastic variable $y$ and independent stochastic variable $\mathrm{x}$, when assuming that the observed value of $x$ is $X$ and the joint probability density function is $f(x, y)$.

$$
\hat{Y}=E\left(\frac{y}{X}\right)=\frac{\int_{-\infty}^{\infty} y f(\mathrm{X}, \mathrm{y}) \mathrm{dy}}{\int_{-\infty}^{\infty} f(\mathrm{X}, \mathrm{y}) \mathrm{dy}}
$$

where $\hat{Y}$ denotes the predicted output of $Y$ when $X$ is the input stochastic variable. Joint density function $f(X, Y)$ can then be evaluated by using the Parzen nonparametric estimation from a sample data set.

$$
f(\mathrm{X}, \mathrm{y})=\frac{\sum_{i=1}^{n} \exp \left[-\frac{\left(\mathrm{X}-\mathrm{X}_{i}\right)^{T}\left(\mathrm{X}-\mathrm{X}_{i}\right)}{2 \sigma^{2}}\right] \exp \left[-\frac{\left(\mathrm{X}-Y_{i}\right)^{2}}{2 \sigma^{2}}\right]}{n(2 \pi)^{\frac{p+1}{2}} \sigma^{p+1}}
$$

where $f(X, Y)$ denotes the estimated value of $f^{\prime}(X, Y), X_{i}$ and $Y_{i}$ are the observed sample data set values of $x$ and $y$ respectively; $n$ is the sample data set size; $p$ is the dimension of $x$; $\sigma$ is the smoothing factor. When replacing $f(X, y)$ with $f^{\prime}(X, y)$ in the equation 17 , I get the predicted output value of $\mathrm{Y}$.

$$
\Lambda(\mathrm{X})=\frac{\sum_{i=1}^{n} \exp \left[-\frac{\left(\mathrm{X}-\mathrm{X}_{i}\right)^{T}\left(\mathrm{X}-\mathrm{X}_{i}\right)}{2 \sigma^{2}}\right] \int_{-\infty}^{\infty} y \exp \left[-\frac{\left(\mathrm{X}-Y_{i}\right)^{2}}{2 \sigma^{2}}\right] \mathrm{dy}}{\sum_{i=1}^{n} \exp \left[-\frac{\left(\mathrm{X}-\mathrm{X}_{i}\right)^{T}\left(\mathrm{X}-\mathrm{X}_{i}\right)}{2 \sigma^{2}}\right] \int_{-\infty}^{\infty} \exp \left[-\frac{\left(\mathrm{X}-Y_{i}\right)^{2}}{2 \sigma^{2}}\right] \mathrm{dy}}
$$

where $\hat{Y}(X)$ is the weight mean of the observed sample data set value $Y_{i}$, and the weight factor of $Y_{i}$ is the square index of the Euclid distance between $X_{i}$ and $X$. MAHC comprises a nonlinear voltage stability error feedback (NVSEF) controller and two nonlinear tracking differentiators (TD), i.e. TDI and TDIl (Goodwin et al. 2000). The first nonlinear tracking differentiator (TDI) can filter the rough pitch angle reference command generated from MAHC model into a smooth and suitable differential signal for the nonlinear pitch controller. The second one can reconstruct the output pitch angle signal and obtain its differential feedback signal. Multivariable adaptive hybrid controller block diagram is shown in figure 11 .

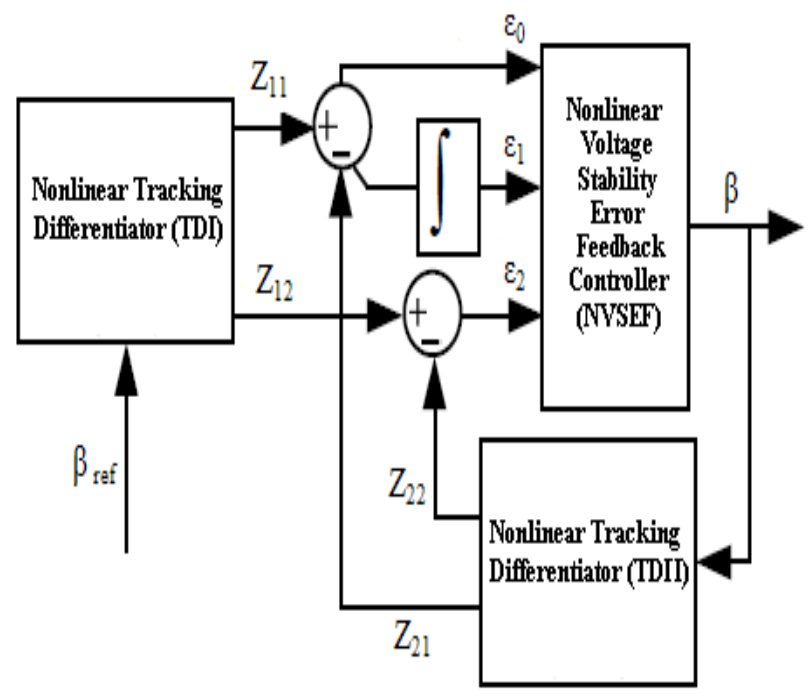

Figure 11. Multivariable adaptive hybrid controller block diagram

As shown in figure 11, the pitch angle reference command is sent to the first nonlinear tracking differentiator (TDI) for nonlinear mapping and two signals $Z_{11}$ and $Z_{12}$ are then extracted from the TDI, where $Z_{11}$ follows the track of the pitch angle reference command and $Z_{12}=Z_{11}$. The output pitch angle signal is sent to the second nonlinear tracking 


\section{differentiator}

TDII and two signals $Z_{21}$ and $Z_{22}$ are then extracted, where $Z_{21}$ follows the track of the output pitch angle signal and $Z_{22}=Z_{21}$. Therefore, the signal error $\varepsilon_{0}$, integral error $\varepsilon_{1}$, and differential error $\varepsilon_{2}$, are generated for the calculation of pitch angle which can be deduced by the nonlinear combination and function of the signal errors $\varepsilon_{0}, \varepsilon_{1}$, $\varepsilon_{2}$. The signal errors $\varepsilon_{0}, \varepsilon_{1}, \varepsilon_{2}$ in this nonlinear pitch controller can be mathematically described as;

$\left\{\begin{array}{l}\varepsilon_{0}=Z_{11}-Z_{21} \\ \varepsilon_{1}=\int_{0}^{t}\left(Z_{11}-Z_{21}\right) d t \\ \varepsilon_{2}=Z_{12}-Z_{22}\end{array}\right.$

The two nonlinear tracking differentiators (TDI and TDII) can be mathematically described as;

$$
\left\{\begin{array}{l}
\dot{Z_{12}}=-r_{1} g\left[Z_{11}-\beta_{r e f}+\frac{Z_{12}\left|Z_{12}\right|}{2 r_{1}}, \theta_{1}\right] \\
\dot{Z_{22}}=-r_{2} g\left[Z_{21}-\beta+\frac{Z_{22}\left|Z_{22}\right|}{2 r_{2}}, \theta_{2}\right]
\end{array}\right.
$$

Output pitch angle can then be obtained from the nonlinear voltage stability error feedback controller as;

$\beta=k_{p} f\left(\varepsilon_{0}, \alpha_{0}, \delta_{0}\right)+k_{i} f\left(\varepsilon_{1}, \alpha_{1}, \delta_{1}\right)+k_{d} f\left(\varepsilon_{2}, \alpha_{2}, \delta_{2}\right)$

Nonlinear functions can be expressed as;

$$
\begin{aligned}
& g(\mathrm{x}, \theta)=\left\{\begin{array}{cc}
\operatorname{sgn}(\mathrm{x}) & |x| \geq \theta \\
x / \theta & |x|<\theta
\end{array}\right. \\
& f(\varepsilon, \alpha, \delta)=\left\{\begin{array}{cc}
|\varepsilon|^{\alpha} \operatorname{sgn}(\varepsilon) & |\varepsilon|>\delta \\
\varepsilon / \delta^{(1-\delta)} & |\varepsilon| \leq \delta
\end{array}\right.
\end{aligned}
$$

where $k_{p}, k_{i}, k_{d}$ are the tunable gain factors, $r_{1}$ and $r_{2}$ are the system coefficients of nonlinear tracking differentiators, respectively. $\delta_{0}, \delta_{1}, \delta_{2}$ are the linear interval indexes of the nonlinear function $f(\varepsilon, \alpha, \delta)$. $\alpha_{0}, \alpha_{1}, \alpha_{2}$ are the nonlinear interval indexes of the nonlinear function $f(\varepsilon, \alpha, \delta)$, respectively.
If $0<\alpha<1$, then the nonlinear function $f(\varepsilon, \alpha, \delta)$ has the characteristic of "high error, small gain factors; low error, large gain factors", while if $\alpha>1$, then the nonlinear function $f(\varepsilon, \alpha, \delta)$ has the characteristic of "high error, large gain factors; low error, small gain factors". The characteristics indicate that the nonlinear function $f(\varepsilon, \alpha, \delta)$ has good ability of suppressing signal error and perturbation. $\theta_{1}, \theta_{2}$ are the linear interval indexes of the nonlinear function $g(x, \theta)$, respectively.

\section{Simulation Results of MAHC}

The proposed MAHC strategies have been developed and validated using Matlab - Simulink program. Mathematical model of MAHC is shown in figure 12.

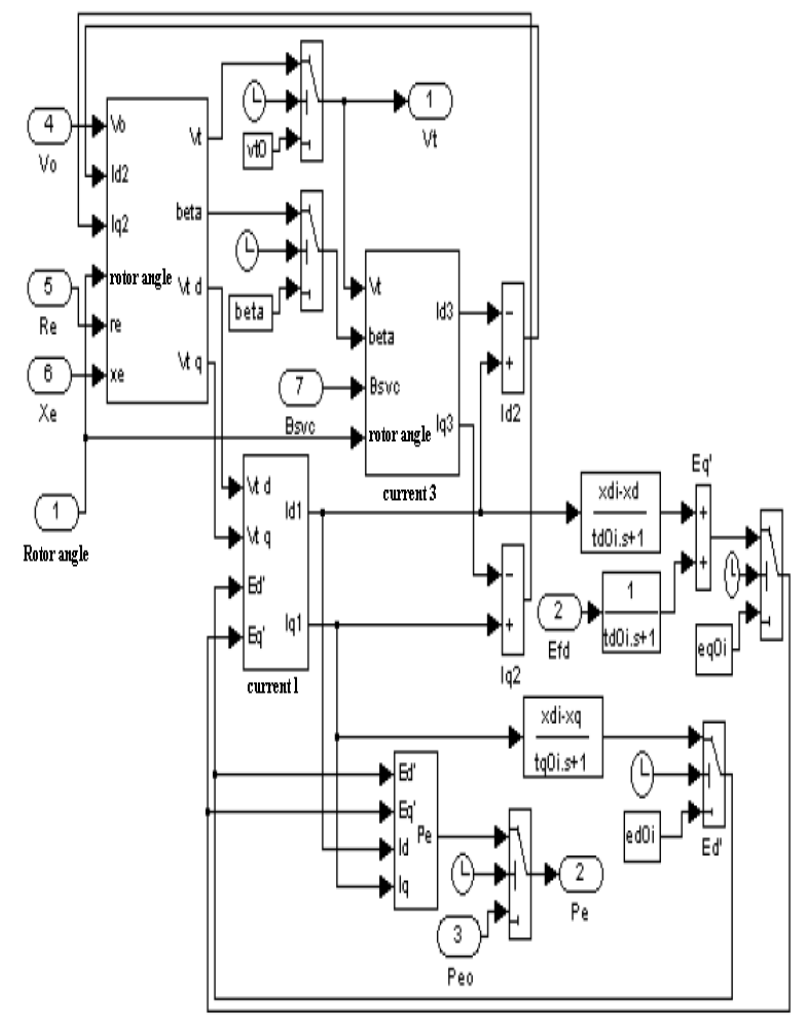

Figure 12. Mathematical model of multivariable adaptive hybrid control

Rotor angular velocity of interconnected power system model is shown in figure 13. According to figure 13, linear control, nonlinear control and MAHC achieve an acceptable rotor angular velocity regulation in the partial load region. However, tracking performance of the conventional linear control and conventional nonlinear control is poor, while the rotor angular velocity can be precisely 
controlled to track the optimum angular velocity by MAHC. Generator voltage of interconnected power system model is shown in figure 14.

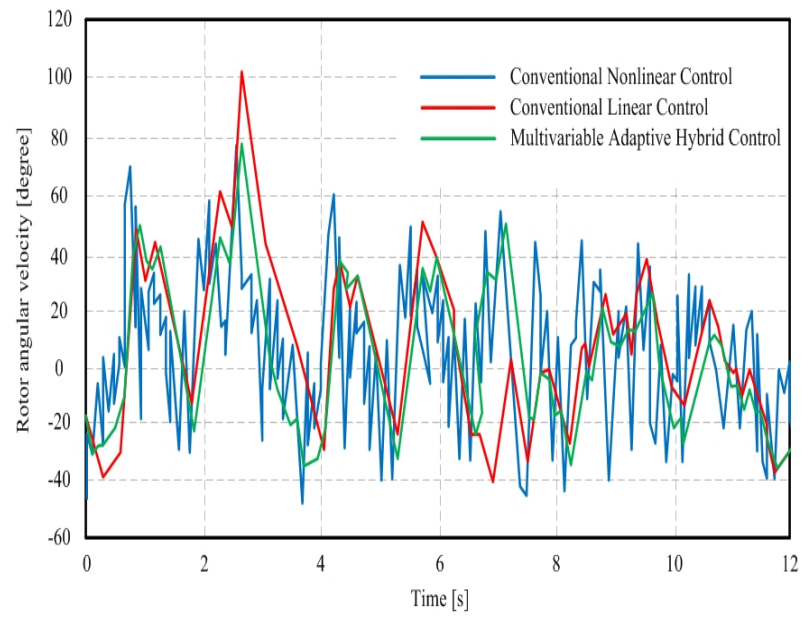

Figure 13. Comparison of rotor angular velocity of power system model

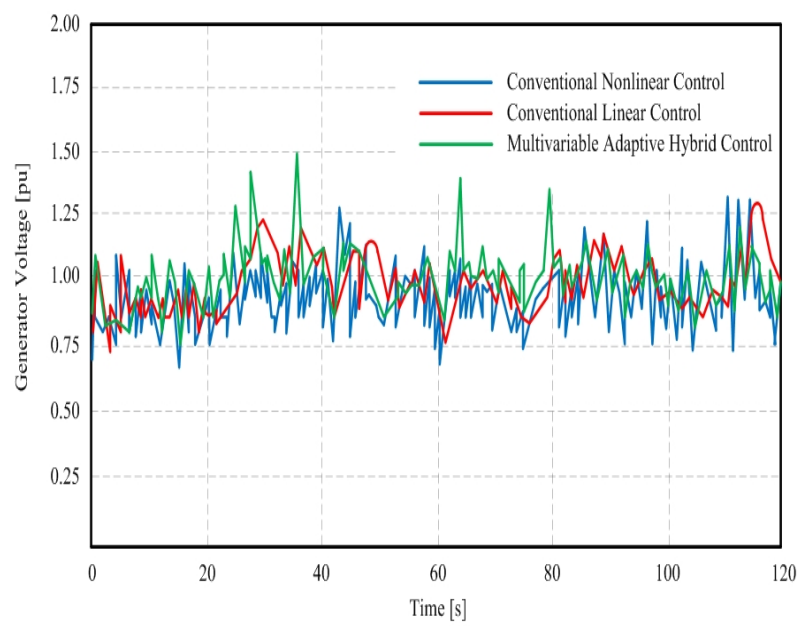

Figure 14. Comparison of generator voltage of interconnected power system model (for $\mathrm{P}=0.95 \mathrm{pu}$, $\mathrm{Q}=0.87 \mathrm{pu}$ )

As shown in figure 14, the generator voltage from the linear and nonlinear controller is always under relatively big deviation to the generator voltage reference command, while the generator voltage derived from the MAHC tracks the reference command more accurately. Active power of interconnected power system model is shown in figure 15 and reactive power of interconnected power system model is shown in figure 16. (Generator voltage $1.05 \mathrm{pu}$ )

According to figure 15 and figure 16, the maximum generator active and reactive power extraction can be achieved by the MAHC. The tracking error is relatively smaller while the generator power extracted from the nonlinear controller has much more deviations from the maximum generator active and reactive power conditions.

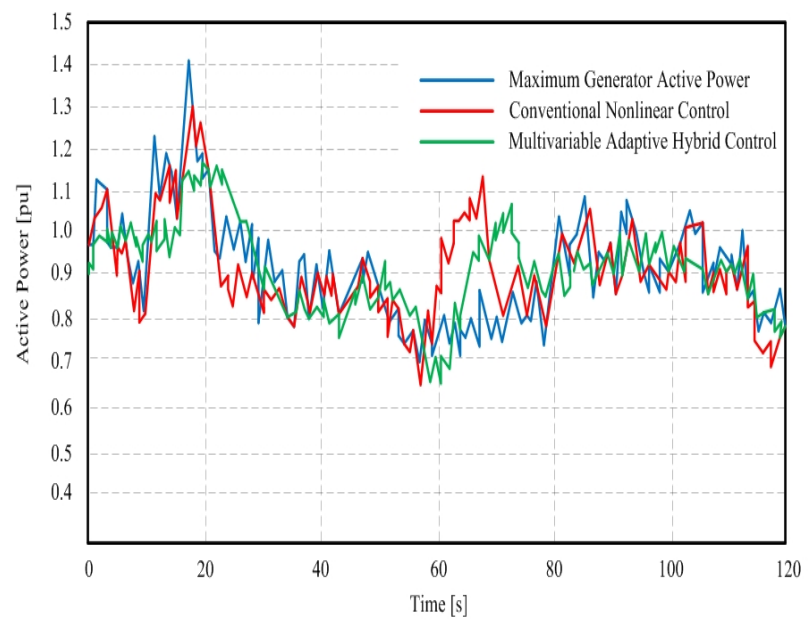

Figure 15.Comparison of active power in interconnected power system model (for generator voltage $1.05 \mathrm{pu}$ )

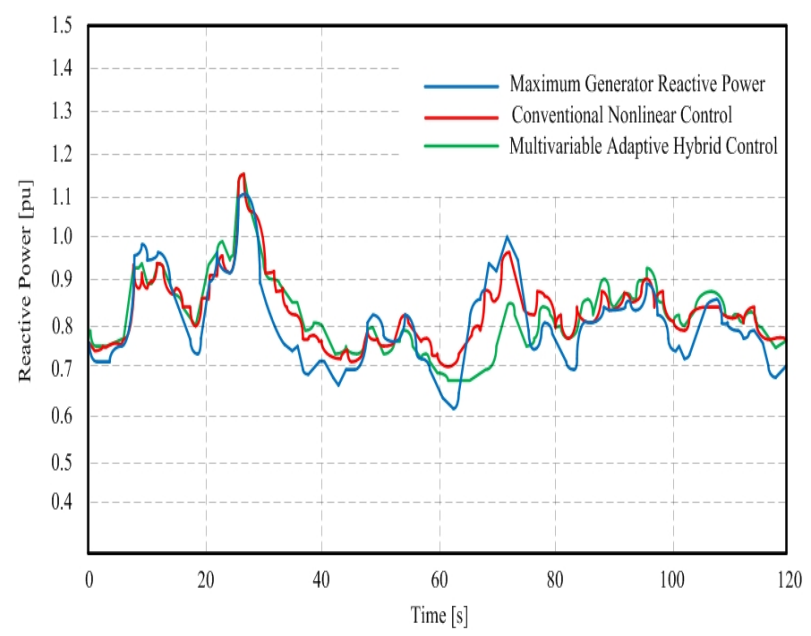

Figure 16. Comparison of reactive power in interconnected power system model (for generator voltage $1.05 \mathrm{pu}$ )

\section{Conclusions}

In this paper, the problem of bifurcation control at the inception of the voltage collapse is studied for interconnected power system by linear, nonlinear and MAHC. Both the generator active and reactive power and generator pitch angle are controlled in partial or full load conditions. Furthermore, an effective MAHC pitch controller is proposed to track the pitch angle reference command in the full load conditions. It is observed that MAHC is more 
suitable for controlling voltage collapse. Voltage collapse is an interconnected power system instability which may arise in different ways for different systems. A variety bifurcation of phenomena, including routes to chaos, has been detected for power system models exhibiting voltage collapse.

At the first level, a linear control input is applied to the interconnected power system for neutralizing the effect of interactions between the power subsystems. Since the power subsystems become decoupled due to the control at the first level, the second level control can be applied in a decentralized way to each of the power subsystems. The control objective at this level is to assure the desired performance and stability for each power subsystem. The final MAHC input, obtained from summation of inputs at both of the levels, guarantee the stability and performance of the overall power system. MAHC which validates that the proposed method is much faster, more accurate and effective than the conventional linear and nonlinear control approach.

\section{References}

Abed, E.H., Hassouneh, M.A., Saad, M.S., 2004. Instability monitoring and control of power systems. Institute for Systems Research, Technical Research Report, TR 36, 1-20.

Aboreshaid, S., Billinton, R., 1999. Probabilistic evaluation of voltage stability. IEEE Trans. PWRS, 14(1), 342-348.

Anders, G.J., 1990. Probability Concepts in Electric Power Systems. John Wiley \& Sons, New York.

Astolfi, A., Karagiannis, D., Ortega, R., 2008. Towards applied nonlinear adaptive control. Annual Reviews in Control, 32(1), 136-148.

Billinton, R., Aboreshaid, S., 1998. Voltage stability considerations in composite power system reliability evaluation. IEEE Trans. PWRS, 13(2), 655-660.

Canizares, C.A., Zambroni de Souza, A.C., Quintana, V.H., 1996. Comparison of performance indices for detection of proximity to voltage collapse. IEEE Trans. PWRS, 11(3), 1441-1447.

Dobson, I. and Chiang, H.D., 1989. Towards a theory of voltage collapse in electric power systems. Systems \& Control Letters, 13(3), 253-262.
Goodwin, G.C., Graebe, S.F., Salgado, M.E., 2000. Control System Design. New Jersey: Prentice Hall, 631-651.

Hussein, A. and Chen, K., 2003. On efficient methods for detecting Hopf bifurcation with applications to power system instability prediction. International Journal of Bifurcation and Chaos in Applied Sciences and Engineering, 13(1), 1247-1253.

Karsenti, L., Lagarrigue, F.L., Bastin, G., 1996. Adaptive control of nonlinear systems with nonlinear parameterization. Systems \& Control Letters, 27(1), 87-97.

Leite da Silva, A.M., Arienti, V.L., 1990. Probabilistic load flow by a multilinear simulation algorithm. IEE Proc. Pt. C, 137(4), 276-282.

Leite da Silva, A.M., Ribeiro, S.M.P., Arienti, V.L., Allan, R.N., Do Coutto Filho, M.B., 1990. Probabilistic load flow techniques applied to power system expansion planning. IEEE Trans. PWRS, 5(4), 276-282.

Liu, L.D., Hu, J.F., He, Z.S., Han, C.L., 2011. A robust controller for synchronization of chaotic system. Journal of Optoelectronics and Advanced Materials, 13(4), 354-358.

Meddad, M., Eddiai, A., Belkhiat, S., Cherif, A., Hajjaji, A., Benahdouga, S., Sassi, Z., Touhtouh, S., 2013. Analysis of micro power generator autonomous PZT with use of sliding mode control. Journal of Optoelectronics and Advanced Materials, 15(5-6), 487-492.

Niglye, N., Peritore, F.S., Soper, R.D., Anderson, C., Moxley, R., Guzman, A., 2006. Considerations for the application of synchrophasors to predict voltage instability. Power Systems Conference: Advanced Metering Protection Control Communication and Distributed Resources PS'06, Clemson, SC, 169-172.

Öztürk, S. and Gencer, Ö.Ö., 2002. Angle \& voltage stability improvement with series compensation. ACTA Press European Power and Energy Systems.

Pagilla, P.R., Dwivedula, R.V., Siraskar, N.B., 2007. A decentralized model reference adaptive controller for large scale systems. IEEE - ASME Transactions on Mechatronics, 12(2), 154-163.

Revel, G., Alonso, D.M., Moiola, J.L., 2008. Bifurcation theory applied to the analysis of power systems. Revista De La Union Matematica Argentina, 49(1), 16-24.

Rubinstein, R.Y., 1981. Simulation and The Monte Carlo Method. John Wiley \& Sons, New York.

Saad, M.S., Hassouneh, M.A., Abed, E.H., Edris, A., 2005. Delaying instability and voltage collapse in power systems using SVCs with washout filter-aided 
feedback. American Control Conference, 6(1), 43574362.

Sheng, Z., Han, Q., Ning, J., 2011. Analysis of pump wavelength drift induced stability problems of cladding - pumped EYDFAs. Optoelectronics and Advanced Materials - Rapid Communications, 5(3), 201-203.

Sobierajski, M., 1994. Probablistic approach to steady state voltage stability of bulk power systems. Proceedings of the Third International Seminar on Bulk Power System Voltage Phenomena, Voltage Stability, Security and Control, Davos, Switzerland, 325-331.

Sun, L.Y., Zhao, J., Dimirovski, G.M., 2009. Nonlinear robust controller design for thyristor controlled series compensation. International Journal of Innovative Computing, Information and Control, 5(4), 981-989.

Thukaram, D., Parthasarathy, K., Khincha, H.P., Norendranath, U., Bansilal, U.A., 1998. Voltage stability improvement: case studies of Indian power Networks. Electric Power Systems Research, 44(1), 35-44.

Tunç, C., 2011. Instability result of a fifth order nonlinear delay system. Optoelectronics and Advanced Materials - Rapid Communications, 5(9), 891-894.

Walve, K., 1986. Modelling of power system components at severe disturbances. International Conference on Large High Voltage Electric Systems (CIGRE), Paper 2, 1-9.

Wang, H.O., Abed, E.H., Hamdan, A.M., 1994. Bifurcations chaos and crises in voltage collapse of a model power system. IEEE Transactions Circuits Systems I, 41(3), 294-302.

Zambroni de Souza, A.C., Canizares, C.A., Quintana, V.H., 1997. New techniques to speed up voltage collapse computations using tangent vectors. IEEE Trans. PWRS, 12(3), 1380-1387. 